\title{
CASE NOTES
}

\section{CORNEO-SCLERAL ULCERATION IN PERIARTERITIS NODOSA*}

\author{
BY \\ J. GIBSON MOORE AND D. SEVEL \\ Edgware General Hospital and the Department of Pathology, Institute of Ophthalmology, \\ University of London
}

OCULAR complications occur in 10 to 20 per cent. of patients with periarteritis nodosa (Gaynon and Asbury, 1943; Wise, 1952), but so far very few cases of either corneal ulceration, corneo-scleritis, or scleritis have been documented, which have been associated with either periarteritis nodosa or the Wegener variety of non-healing granuloma of the nose (Harbert and McPherson, 1947; Ingalls, 1951; Goar and Smith, 1952; Cogan, 1955; Cury, Breakey, and Payne, 1956; Cutler and Blatt, 1956; Frayer, 1960; McCarthy, 1961; Wyble and Schimek, 1962).

There is some similarity in the clinical findings in cases of Wegener's granulomatosis. Straatsma (1957) recorded five cases of corneo-scleral infiltration, with subsequent ulceration and furrow formation in two of them. As our case shows no evidence of granulomata in the upper respiratory tract, it clearly does not fall into the category of Wegener's granulomatosis. The purpose of presenting it is to emphasize the value of the pathological report on the eye with special reference to subsequent investigation and diagnosis.

\section{Case Report}

A house-wife aged 75 years was admitted to the medical wards of the Edgware General Hospital on June 12,1960, with a history of weight loss and malaise over a period of one month.

Physical Examination.-The jugular venous pressure was raised and the liver enlarged, and there was pitting oedema of the ankles. The blood pressure was raised (220/120) and there was a mild pyrexia.

\section{Laboratory Investigations}

BLOOD.-The patient was anaemic (Hb 9.3 g. per cent.). White cell count and differential count-normal. Blood urea $97 \mathrm{mg}$. per cent.

URINE.-Heavily loaded with albumen, numerous white and red blood cells, and occasional granular casts.

$X$-RAYS. - The lung fields revealed segmental atelactasis, and the heart was enlarged.

Diagnosis.-Congestive cardiac failure associated with hypertension and renal insufficiency.

Treatment.-Digitalization with diuretics and antibiotics.

Progress.-The cardiac condition improved and the blood pressure returned to normal limits, and the patient was discharged on July 2, 1960.

Some weeks later she complained of a painful watering left eye.

\footnotetext{
* Received for publication August 18, 1965.
} 
Ophthalmological Examination.-A deep indolent ulcer, the base of which was filled with necrotic debris (Fig. 1), was found at the limbus at 3 o'clock.

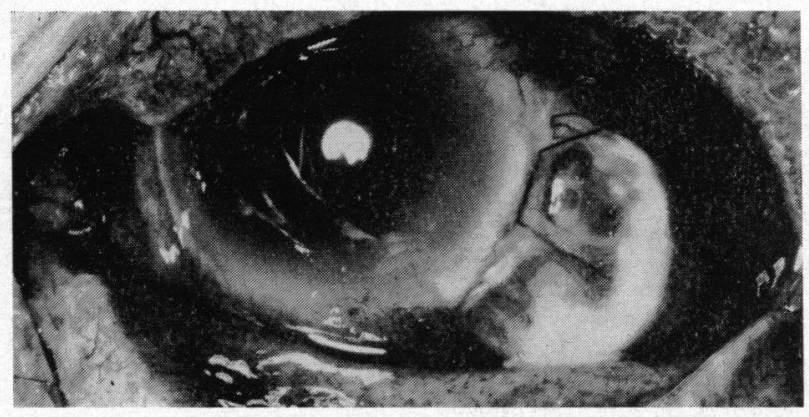

FIG. 1.-Left eye, showing scleral thinning on nasal side at 3 o'clock.

Treatment.-In view of the imminent danger of rupture of the globe, the patient was immediately re-admitted to hospital. She was treated conservatively (gutt. atropine 1 per cent. twice daily and gutt. hydrocortisone 2 drops hrly) but the response was unfavourable.

Biopsy.-Because of the retrogressive nature of the ulcer a biopsy of the crater margin was sent to the Pathology Department of the Edgware General Hospital. The sections showed a fragment of corneal epithelium with subacute and chronic inflammatory reaction in the subconjunctival connective tissue, a large proportion of the inflammatory cells being eosinophils. There was no evidence of malignancy and the histology was not characteristic of a rheumatoid lesion.

Operation.-The ocular pain became severe and as the eye was about to perforate at the site of the ulcer, it was decided on September 28, 1960, to enucleate it.

The globe was sent to the Institute of Ophthalmology, London, for pathological investigation.

\section{Pathological Findings}

Macroscopical Examination.--Situated between 2 and 5 o'clock at the limbus and extending as far as the equator, there was scleral roughness and thickening, but no actual

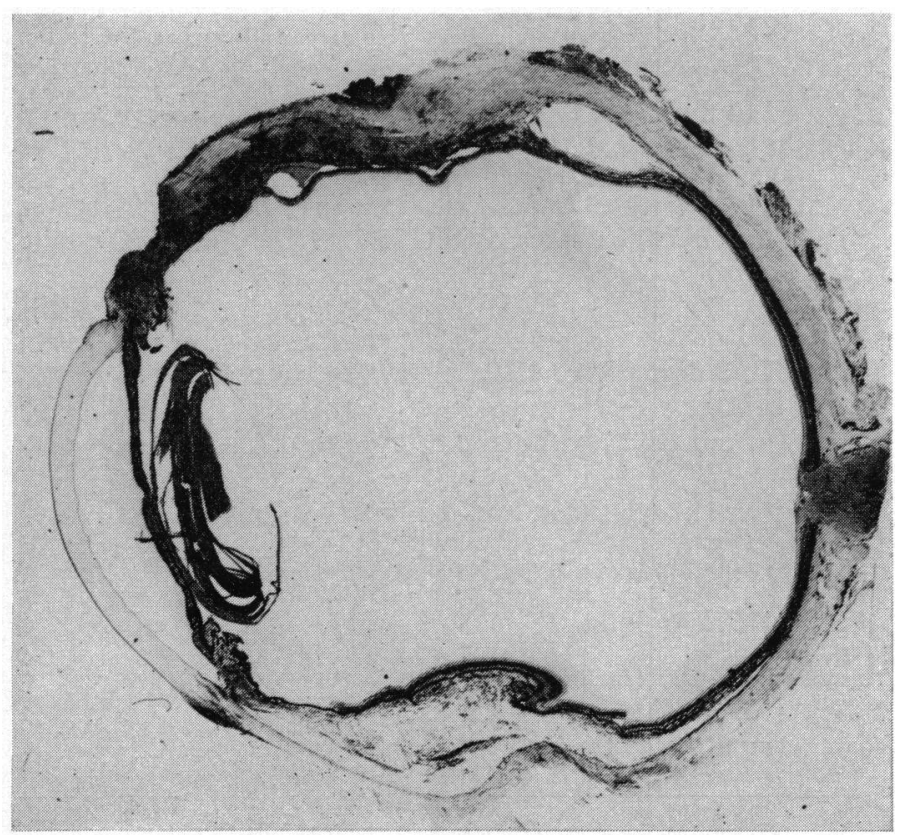
perforation. The globe was opened vertically and there was folding and oedema of the retina and choroid (Fig. 2).

Fig. 2.- Vertical section of whole globe, showing extent of scleral reaction. Haematoxylin and eosin. $\times 3$. 
Microscopical Examination.-The sections showed a chronic granulomatous reaction of the sclera extending from the limbus to the equator with involvement of the pars ciliaris, retina, and choroid. The affected sclera was thickened and disorganized and within its substance were many necrotic foci and inflammatory cells (particularly lymphocytes, plasma cells, a few polymorphonuclear leucocytes, and eosinophils), some in palisade formation and some separated from each other by degenerate scleral strands (Figs 3 and 4). A segment of sclera was absent and the anterior edge of the defect epithelialized, but no perforation was present. The retina showed peripheral cystic degeneration, oedema of the nerve fibre layer, and detachment at the site of the lesion; the subretinal space contained an eosinophilic exudate, while on the opposite side the retina was thrown into folds. There was evidence of endarteritis and periarteritis of the thickened choroidal vessels, particularly in relation to the scleral reaction. An albuminous exudate was present in the anterior chamber, the angle of which was completely occluded on the side of the lesion, while the hypercellular iris exhibited an incomplete fibrovascular membrane on its anterior surface and posterior synechiae to the cataractous lens. The vitreous cavity contained an albuminous exudate in which there were a few inflammatory cells, and the optic nerve was free from inflammatory changes.

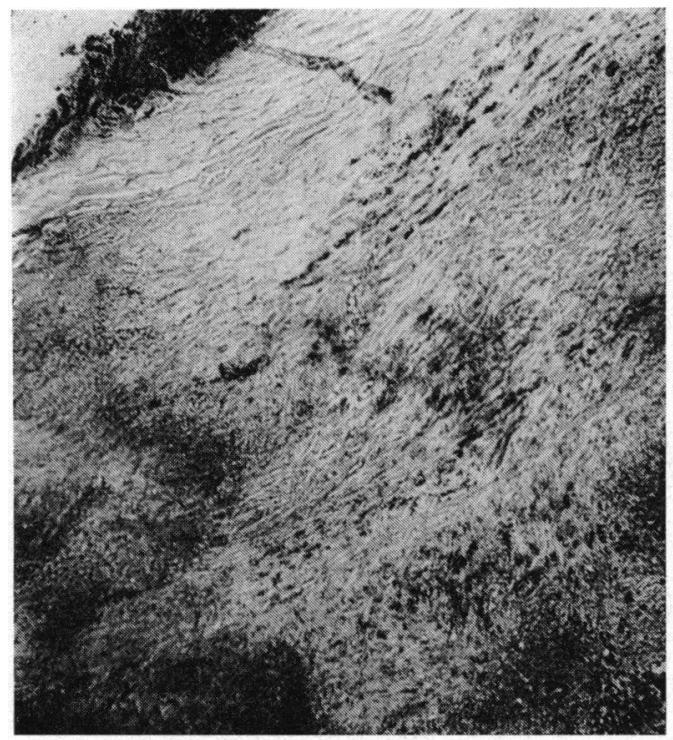

FIG. 3.-High-power view, showing disorganization of sclera, necrotic foci, and palisading of inflammatory cells. Haematoxylin and eosin. $\times 40$.

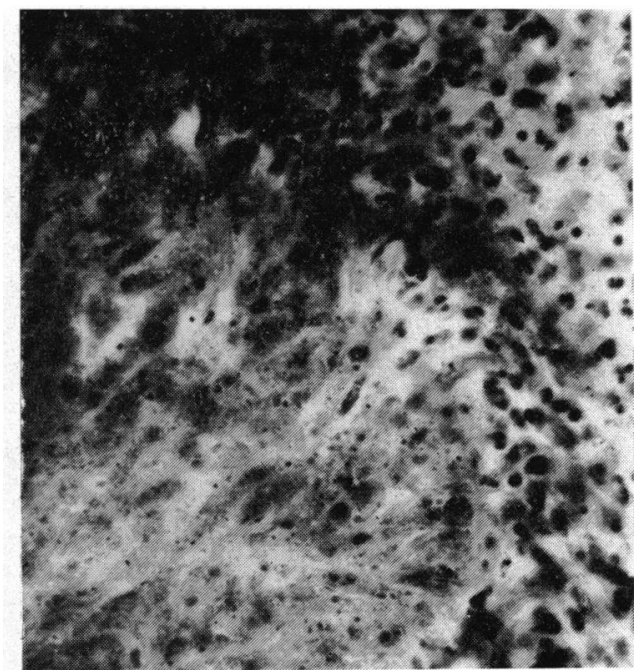

Fig. 4.-Higher-power view, showing scleral necrosis and palisading of inflammatory cells. Haematoxylin and eosin. $\times 600$.

The pathological appearance of the eye was suggestive of that seen in rheumatoid arthritis, periarteritis nodosa, and non-healing granuloma of the nose, and it gave a new directive for further investigation and re-assessment.

Further History.-On the basis of these ocular features the patient was again admitted to the hospital. She complained of a continued weight loss and poor appetite, and since her last admission had suffered a tingling sensation in her fingers and toes and a generalized erythematous skin rash. Examination revealed that the patient was still in congestive cardiac failure with hypertension and some renal failure, the general medical observations being much the same as at the first admission. No abnormality was detected in either the peripheral or central nervous system. An otolaryngologist found no upper respiratory tract lesions; the nasal mucosa was pale but there was no 
obvious ulceration to suggest a granulomatous lesion of the nose. She complained however of an episode of transient deafness which was of unknown duration but sufficiently marked to be distressing.

Additional Blood Investigations.-Erythrocyte sedimentation rate $55 \mathrm{~mm}$. in 1 hour (Westergren); alpha $_{2}$ and gamma globulins raised; C-reactive protein ++ ; fluorescent test for antinuclear factors weakly positive; Ouchterlony test against scleral antigen negative.

Diagnosis.-Periarteritis nodosa.

Treatment.-The patient was started on a regime of systemic steroids, to which she responded reasonably well, so much so that she was discharged on February 8, 1961.

Termination. -3 months later the patient died. There was no post mortem examination.

\section{Comment}

The typical histological features of scleral necrosis surrounded by a granulomatous inflammatory reaction and palisading of the nuclei are suggestive of rheumatoid arthritis, periarteritis nodosa, or non-healing granuloma of the nose (Wegener type). With reference to this case, and medical examination, a diagnosis of periarteritis nodosa is most likely.

The value of the corneo-conjunctival biopsy is difficult to assess. Considered in the light of the systemic findings, the histological features, with the distinct predominance of eosinophils, intimates the possibility of these eye signs being part of a generalized allergic phenomenon. A deeper scleral biopsy might have revealed a more typical picture of a necrotizing lesion of the sclera surrounded by a granulomatous reaction. However, deep scleral biopsies are fraught with such complications as immediate perforation at operation, or delayed healing of the surgical wound, because of the avascularity of the sclera and the nature of the pathology. On the other hand, it is interesting to note that Mundy, Howard, Stillman, and Bevans (19.51) effectively obtained successive scleral biopsies from a case of scleromalacia perforans and was thus able to study the effects of cortisone on the condition. It is hoped in the future to obtain biopsies from further cases of scleritis and so to assess the merits of the procedure, especially as it may help in the early diagnosis of periarteritis nodosa.

A further interesting feature of this patient is the history of deafness. Cogan (1945) described a condition of non-syphilitic interstitial keratitis and deafness occurring in young adults, which may be associated with periarteritis nodosa. Oliner, Taubenhaus, Shapira, and Leshin (1953) considered a variant of the disease, where, in addition to the deafness and interstitial keratitis, there was a necrotizing nodular scleritis. In our case, the deafness appears to have been transient and, as the patient was not in the recognized age group, it is unlikely that the case is an example of this syndrome.

\section{Summary}

The histopathological examination of an eye from a case of periarteritis nodosa is described, with special reference to the value of the report in subsequent investigation and diagnosis.

We should like to thank Prof. Norman Ashton for allowing us to use the pathological material, Mr. V. Ellwood for technical assistance, and Miss E. FitzGerald for secretarial help. 


\section{REFERENCES}

CogAn, D. G. (1945). Arch. Ophthal. (Chicago), 33, 144.

(1955). Trans. Amer. ophthal. Soc., 53, 321.

Cury, D., Breakey, A. S., and Payne, B. F. (1956). A.M.A. Arch. Ophthal., 55, 261.

Cutler, W. M., and BlatT, I. M. (1956). Amer. J. Ophthal., 42, 21.

FraYer, W. C. (1960). Arch. Ophthal. (Chicago), 64, 58.

Gaynon, I. E., and Asbury, M. K. (1943). Amer. J. Ophthal., 26, 1072.

GoAR, E. L., and SMITH, L. S. (1952). Ibid., 35, 1619.

HARbert, F., and MCPherson, S. D. (1947). Ibid., 30, 727.

Ingalls, R. G. (1951). Trans. Amer. Acad. Ophthal. Otolaryng., 55, 630.

MCCARThY, J. L. (1961). Amer. J. Ophthal., 51, 60.

Mundy, W. L., Howard, R. M., Stillman, P. H., and Bevans, M. (1951). A.M.A. Arch. Ophthal., $45,531$.

Oliner, L., Taubenhaus, M., Shapira, T. M., and Leshin, L. (1953). New Engl. J. Med., $248,1001$.

StraAtsma, B. R. (1957). Amer. J. Ophthal., 44, 789.

Wise, G. N. (1952). A.M.A. Arch. Ophthal., 48, 1.

Wyble, M., and Schimek, R. A. (1962). Trans. Amer. Acad. Ophthal. Otolaryng., 66, 632. 